\title{
ELECTROPHYSIOLOGICAL PROPERTIES OF IDENTIFIED CELLS IN THE IN VITRO OLFACTORY EPITHELIUM OF THE TIGER SALAMANDER ${ }^{1}$
}

\author{
LEONA M. MASUKAWA, BRITTA HEDLUND, ${ }^{2}$ AND GORDON M. SHEPHERD \\ Section of Neuroanatomy, Yale University School of Medicine, New Haven, Connecticut 06510
}

Received March 29, 1984; Revised July 20, 1984; Accepted July 25, 1984

\begin{abstract}
An in vitro preparation of the salamander olfactory epithelium has been developed for electrophysiological analysis. Intracellular measurements of membrane properties of the main epithelial cell types have been carried out, combined with Lucifer Yellow injections.

The most prevalent type of cell had a high resting membrane potential and relatively low input resistance. This cell never discharged impulses, either spontaneously or to injected current. Lucifer Yellow injections identified this cell type as a supporting cell. A less frequent type had a medium resting potential and a very high input resistance. This type always discharged impulses in response to injected depolarizing current. Lucifer Yellow injections identified this cell type as an olfactory receptor neuron.

The least frequent type had a medium resting potential and a high input resistance. It never generated action potentials. This nonspiking type was tentatively identified as an immature receptor neuron in the process of differentiating from basal stem cells in the epithelium.

These are the first results to document physiological properties for the main cell types and morphological identification of two of the types in the same preparation of the olfactory epithelium. Our results support previous suggestions regarding the glial-like properties of the supporting cells. The membrane properties of the receptor neurons appear to be well suited for mediating the olfactory sensory response of these cells.
\end{abstract}

The vertebrate olfactory epithelium is of unique physiological interest. It contains the only neurons in the nervous system directly exposed to the external environment. These neurons transduce a variety of molecular stimuli with extreme sensitivity and selectivity (cf. Gesteland et al., 1965; Getchell and Shepherd, 1978; Graziadei, 1971). In addition to the receptor neurons, the epithelium contains stem cells which give rise to new receptor neurons (Graziadei and Monti Graziadei, 1978), and a large population of supporting cells which undoubtedly have important physiological functions (cf. Simmons et al., 1981; Simmons and Getchell, 1981a, 1981b).

Due to the small size and inaccessibility of the olfactory cells within the nasal cavity, experimental analysis of their physiological properties has been very limited. The few intracellular studies to date have been carried out in in vivo preparations, and have given preliminary data on electrical properties and sensory responses (Suzuki, 1977; Getchell, 1977; Trotier and

\footnotetext{
${ }^{1}$ This work was supported by Research Grants NS-07609 and NS10174 of the National Institute for Neurological and Communicative Disorders and Stroke. We thank Arthur Belanger for computer programming and Alfred Mueller for secretarial assistance. We are also grateful to Drs. Thane Benson, Ellen Lewis, and Patricia Pedersen for helpful suggestions concerning the histological procedures and Dr. John $S$. Kauer for valuable discussion.

${ }^{2}$ On leave of absence from the Department of Biochemistry, Arrhenius Laboratory, University of Stockholm, S-106 91 Stockholm, Sweden.
}

MacLeod, 1983). We have therefore developed an in vitro preparation of the salamander olfactory epithelium, in order to analyze systematically the membrane properties of the epithelial cells. In this paper, we have determined the electrical properties of the main types of epithelial cells, and show how they are correlated with the main types of morphologically identified cells. This provides a basis for not only further analysis of mechanisms of transduction of molecular stimuli into neural responses, but also for studying the changes in physiological properties during turnover of the receptor neurons, and the dramatic changes that take place during injuryinduced degeneration and regeneration as will be described in the following paper (Masukawa et al., 1984). A preliminary report of some of these results has appeared (Masukawa et al., 1983).

\section{Materials and Methods}

The olfactory epithelium of Ambystoma tigrinum was removed as described previously (Masukawa et al., 1983) and mounted on Sylgard (Dow Corning) in a recording chamber. It was perfused by normal oxygenated Ringer's solution (140 $\mathrm{nm} \mathrm{NaCl}, 1.82 \mathrm{mM} \mathrm{KCl}, 3.6 \mathrm{~mm}$ $\mathrm{CaCl}_{2}, 0.71 \mathrm{mM} \mathrm{MgCl}, 26 \mathrm{mM} \mathrm{NaHCO}, 11 \mathrm{mM}$ glucose) and bubbled with $95 \% \mathrm{O}_{2}, 5 \% \mathrm{CO}_{2}, \mathrm{pH} 7.3$. Microelectrodes were fabricated on the Brown-Flaming puller (Sutter Instruments) and filled with $4 \mathrm{M}$ potassium acetate; they had tip resistances of 150 to 200 megohms. An electrode was lowered by a stepping microdrive (Transvertex, Sweden) with $2-\mu \mathrm{m}$ steps. Cell penetrations, after transient increase of capacitance feedback, were indicated by an abrupt change in the electrode potential. Cells were described based on several criteria. They were the relative depth of penetration, magnitude of the resting membrane 
potential and input resistance, action potential generation, and the current voltage relationship. A conventional intracellular recording setup was used. Current was passed through the recording electrode using an active bridge circuit amplifier which was capable of balancing electrode tip resistance up to 300 megohms.

The data was recorded on FM tape (bandwidth: DC to $5000 \mathrm{~Hz}$ ) and digitized and stored in a LSI $11 / 23$ computer. A program written in Basic 23 (Cheshire Data) was used for data acquisition, analysis, and display. Data analysis included calculation of the time constant and current-voltage relations for the different cells studied. The bandwidth of the FM tape recorder did not affect the calculation of the membrane time constant; however, it did limit the analysis of possible equalizing time constants to those slower than approximately $0.3 \mathrm{msec}$.

Lucifer Yellow was injected in order to identify cells after electrical recordings. The shanks of the recording electrodes were filled with $5 \%$ Lucifer Yellow (Sigma) in $1 \mathrm{M} \mathrm{LiCl}$ and the remaining volume was filled with $1 \mathrm{M} \mathrm{LiCl}$. The tip resistances were in excess of 250 megohms; however, they were sufficiently electrically quiet to allow definitive electrical identification of the recorded cells. Hyperpolarizing currents of 0.2 to $1.0 \mathrm{nA}$ were passed using either current pulses of 750 msec duration on, 250-msec off, repeated for up to $5 \mathrm{~min}$, or direct current with a duration of 1 to $2 \mathrm{~min}$. After injection, the tissue was fixed in $2.6 \%$ paraformaldehyde, $0.06 \mathrm{M}$ sodium phosphate buffer, and $1 \%$ calcium chloride for $1 \mathrm{hr}$. The tissue was then embedded in $26 \%$ sucrose and $12 \%$ gelatin, and sectioned on a freezing microtome at a thickness of 60 to $80 \mu \mathrm{m}$. Serial sections were mounted in $75 \%$ glycerol in phsophate-buffered saline and viewed with a fluorescence microscope (Olympus).

\section{Results}

\section{Morphology of the normal epithelium}

The main cellular components of the normal olfactory epithelium of the salamander are shown in the photomicrograph of Figure 1. At the free (upper) surface is a thin lightly stained mucus $(M)$ layer containing the olfactory receptor cilia and supporting cell microvilli. Also seen is a thin layer comprising the terminal knobs, or vesicles $(V)$, of the olfactory receptor dendrites. The most superficial cell body type is the supporting cell $(S)$, represented by elongated nuclei. Throughout the middle depths of the epithelium are the nuclei of the receptor neurons $(R)$, which are more rounded. At the deepest level are occasional basal cells $(B)$ with dark nuclei. In addition, the cells and ducts of Bowman's glands $(B G)$ are present.

It can be seen that a micropipette inserted from the mucosal surface will likely encounter, in succession, first the cell bodies of supporting cells, followed by receptor and basal cells. This was an aid in cell identification, as described below.

\section{Electrophysiological recordings}

Three categories of physiological properties were identified in intracellular recordings from the normal olfactory epithelium of the tiger salamander. Two of these were described previously in a preliminary study (Masukawa et al., 1983). We have further characterized these two cell types and identified them morphologically with intracellular injections of Lucifer Yellow as supporting cells and receptor neurons. In addition, a nonspiking cell has been characterized, which we tentatively correlate with immature receptor neurons.

Supporting cells. Figure 2 (inset) illustrates the electrical response of this cell type to injected current pulses. These cells did not generate action potentials in response to depolarizing currents of high intensity, although relatively large currents were required to depolarize these cells due to their low resting input resistances. The average input resistance was usually in the range of 10 megohms or less and the resting membrane potentials were -80 to $-120 \mathrm{mV}$. The input resistances were clearly low, and the resting potentials were relatively high, in comparison to the other cell types encountered in the epithelium, as will be described below. The current-voltage (I-V) plots were close to linear for currents up to approximately $1 \mathrm{nA}$ (see
Fig. 2); above this, there was significant deviation. This could reflect breakdown of membrane properties with these amounts of current in these very small cells, electrode rectification, or rectification of electrical synapses (see "Discussion"). Analysis of the charging transient (Fig. 3) gave an average value of 1.9 msec for the membrane time constant (see also Table 1). Note particularly the absence of deviation from the linear plot at shorter time intervals, indicating lack of significant equalizing time constants. Although we could not analyze equalizing time constants briefer than approximately $0.3 \mathrm{msec}$ (see "Materials and Methods"), this typical result indicates that these cells are electrotonically relatively compact (see "Discussion").

Cells showing these properties were injected with Lucifer Yellow to identify them by their position within the epithelium and their general cellular morphology. A typical example is shown in Figure 4. The shape and position of the injected cell are comparable to those of a supporting cell as described by Graziadei and Monti Graziadei (1976) from light microscopic data from the tiger salamander. As can be seen from the photomicrographs under combined bright field and fluorescence, in which the relative position of the injected cell is clearly seen, the cell body is located in the upper third of the epithelium, immediately below the mucosal surface. From depth measurements during the electrophysiological recordings, these cells were found to be encountered relatively near the point of contact of the recording tip with the mucosal surface. In the injected cells ( $n=7$ ), the supporting cell processes could be seen to course through most of the thickness of the epithelium. A majority of the cells penetrated in normal epithelium were supporting cells by their electrical characteristics (see Table 1).

Receptor neurons. Another cell type, with distinctly different electrical properties from the supporting cells, was also frequently seen (see Table 1). The resting membrane potentials were substantially lower than those of the supporting cell ( 40 to $60 \mathrm{mV}$ ), but the input resistances were high, usually above 100 megohms. In addition, the most striking difference between this type of cell and the other cell types was that it generated action potentials. These were characteristically greater than 60 $\mathrm{mV}$ in amplitude and $5 \mathrm{msec}$ in duration (Fig. 5). They had a relatively smooth rising phase and were generated repetitively in response to depolarizing current pulses. The discharge was slowly adapting, being maintained at a relatively constant frequency throughout the applied pulse. The frequency increased with more intense depolarizing currents; in the example in Figure 5, the frequency was raised from approximately 25 $\mathrm{Hz}$ (upper) to $35 \mathrm{~Hz}$ (lower). With higher depolarization, a decrement of spike amplitude was commonly observed (see lower trace).

The current-voltage relationships displayed by these cells are illustrated in Figure 6 . In the hyperpolarizing range, the relationship was linear. A similar relationship was also seen previously for this type of cell (Suzuki, 1977; Trotier and MacLeod, 1983). Nonlinearity occurred above the resting membrane potential (see "Discussion"). Below resting potential, in a depolarizing direction, the linear relation held until threshold for impulse initiation was reached (see Fig. 6).

Analysis of the charging transient in response to a current step is illustrated in Figure 7. The analysis gave an average value of $4.2 \mathrm{msec}$ for the membrane time constant (see Table 1). Measurements of the decay transients at the off of the current pulse gave a similar value. This value was significantly longer than the value for the supporting cells. In none of the cells analyzed was there evidence of a significant equalizing time constant at shorter time periods.

This type of cell was identified morphologically as a receptor neuron by Lucifer Yellow injections, as illustrated in the micrographs in Figure 8 . The identification was based on the elliptical cell body and bipolar morphology (Fig. 1). A dendrite 


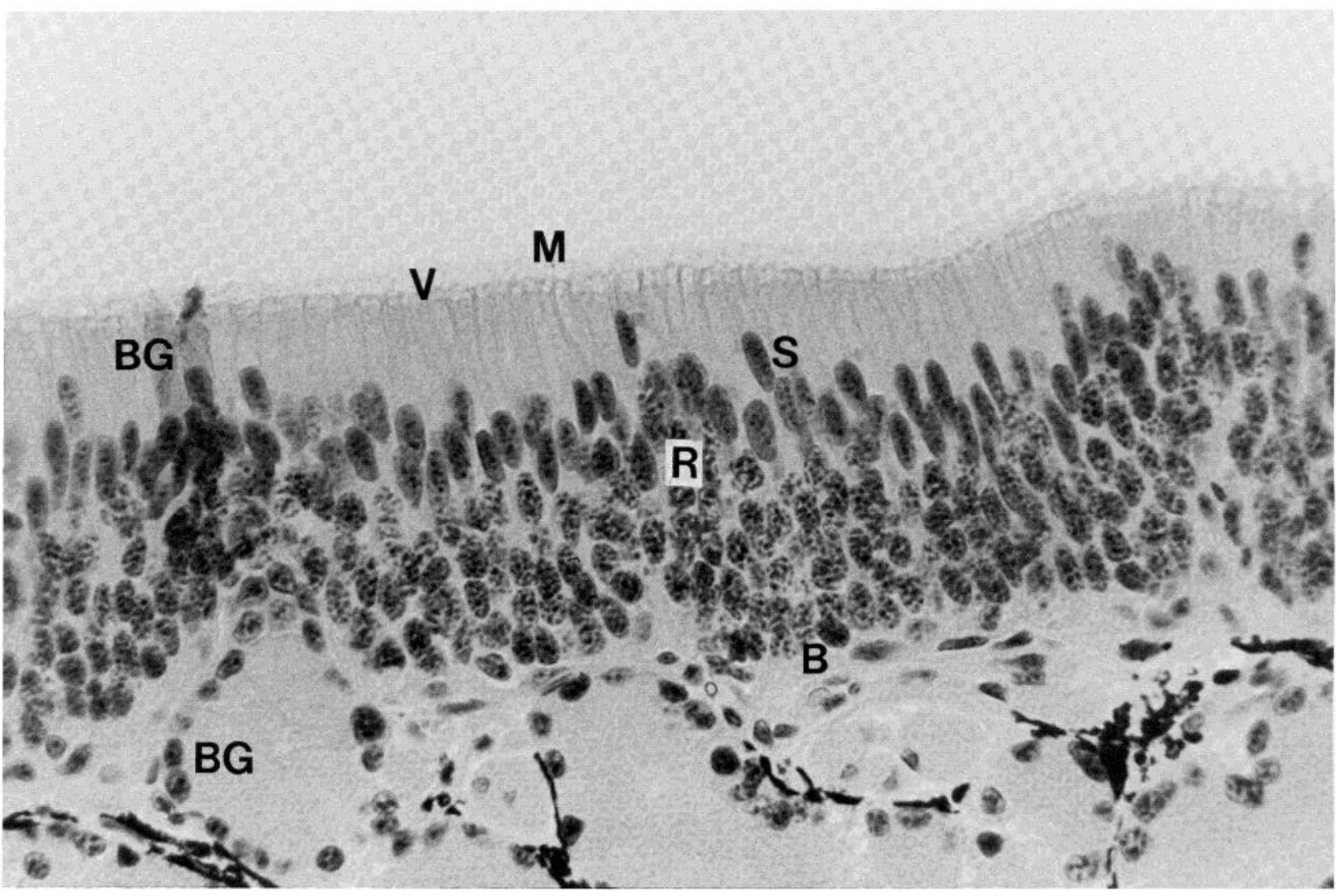

Figure 1. Section of the normal olfactory epithelium of tiger salamander. The tissue was embedded in paraffin, cut at $6 \mu \mathrm{m}$, and stained with hemotoxylin and eosin. Covering the surface of the epithelium is a thin mucus layer $(M)$. At the surface is a thin layer comprising the terminal knobs, or vesicles $(V)$ of the receptor neurons. Below the surface one encounters first a layer of nuclei of supporting cells $(S)$. The receptor neuron cell bodies $(R)$ with their elliptically shaped cell nuclei make up a broader zone in the central third of the epithelium. Basal cells $(B)$ are thinly distributed along the basal lamina. Bowman's glands $(B G)$ are found in the submucosa, and extend their ducts to the surface. Magnification $\times 400$.

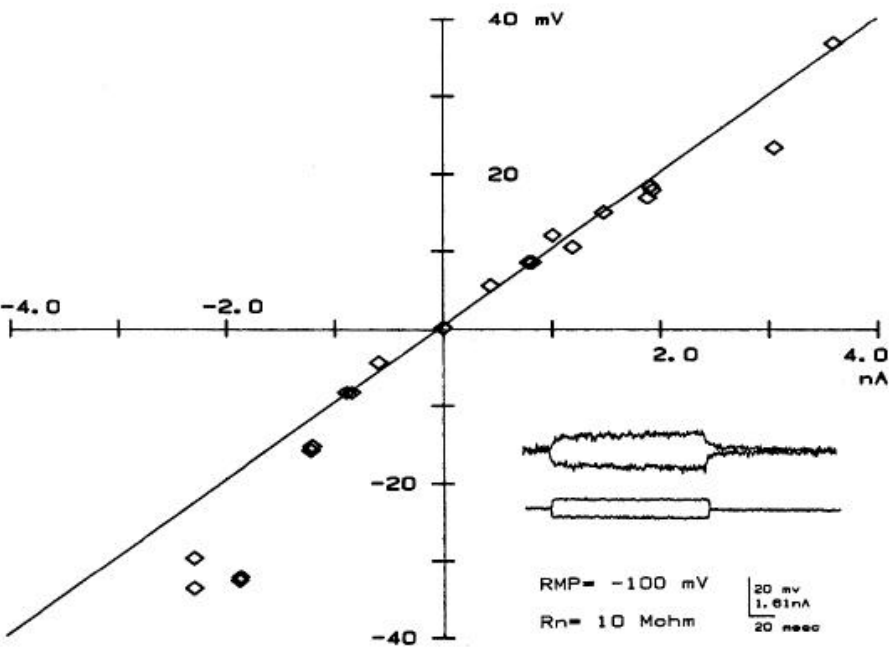

Figure 2. Electrical properties of a supporting cell. The graph shows current-voltage relations measured during the plateau phase of the responses (example in inset). The slope resistance for this cell was estimated to be 10 megohms. In the inset, the lower traces show the current monitor of the intracellularly injected current; the upper traces show corresponding depolarizing (up) and hyperpolarizing (down) responses of this cell. Action potential generation was not present in this cell type. $R M P$, resting membrane potential; $R n$, input resistance.

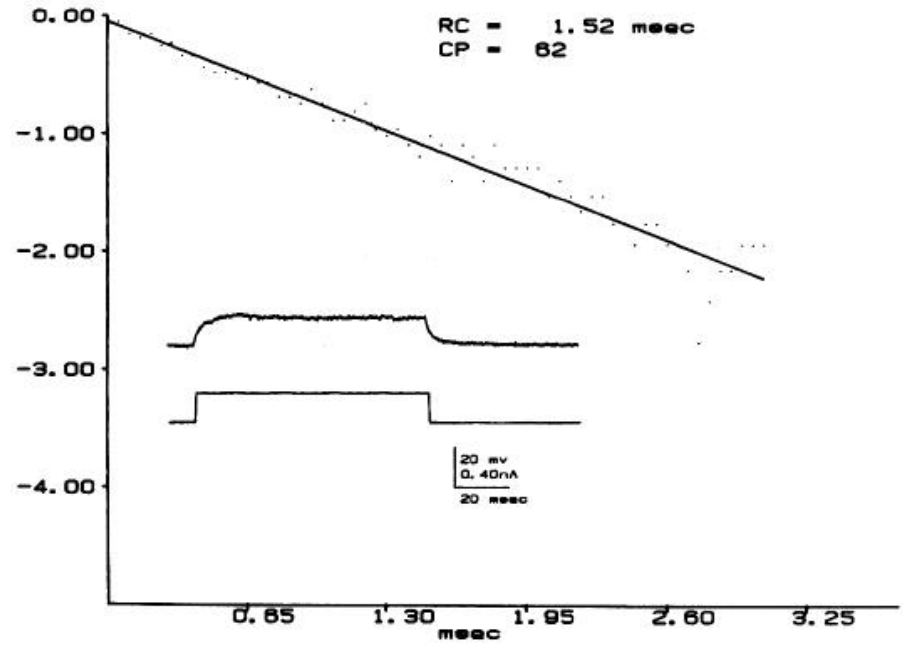

Figure 3. Analysis of the charging transient for a supporting cell. Representative response to a current pulse is shown in the inset. On the ordinate is the difference between the recorded and maximal (plateau) voltage response, normalized for the maximal response. On the abscissa is the time from the onset of response, in milliseconds. The plotted data can be fitted with a single line, which gives the value of the time constant $(R C)$ (see Rall, 1977). $C P$, number of data points. 
TABLE I

Electrical properties of three main cell types from the normal olfactory epithelium of the tiger salamander

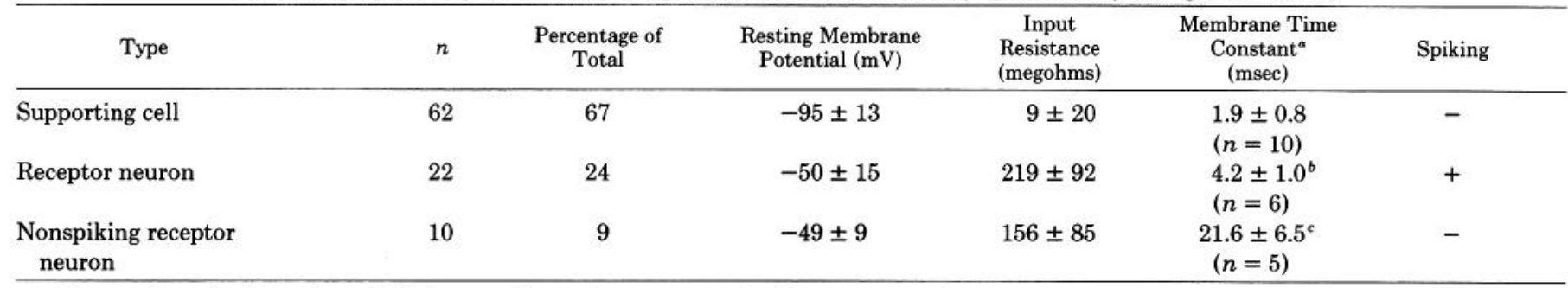

${ }^{a}$ The number of cells, $n$, for which the membrane time constant has been estimated is in parentheses.

${ }^{b} p=0.001$ compared to the values for supporting cell and nonspiking receptor neuron.

${ }^{c} p=0.001$ compared to the values for receptor neuron and supporting cell.

A

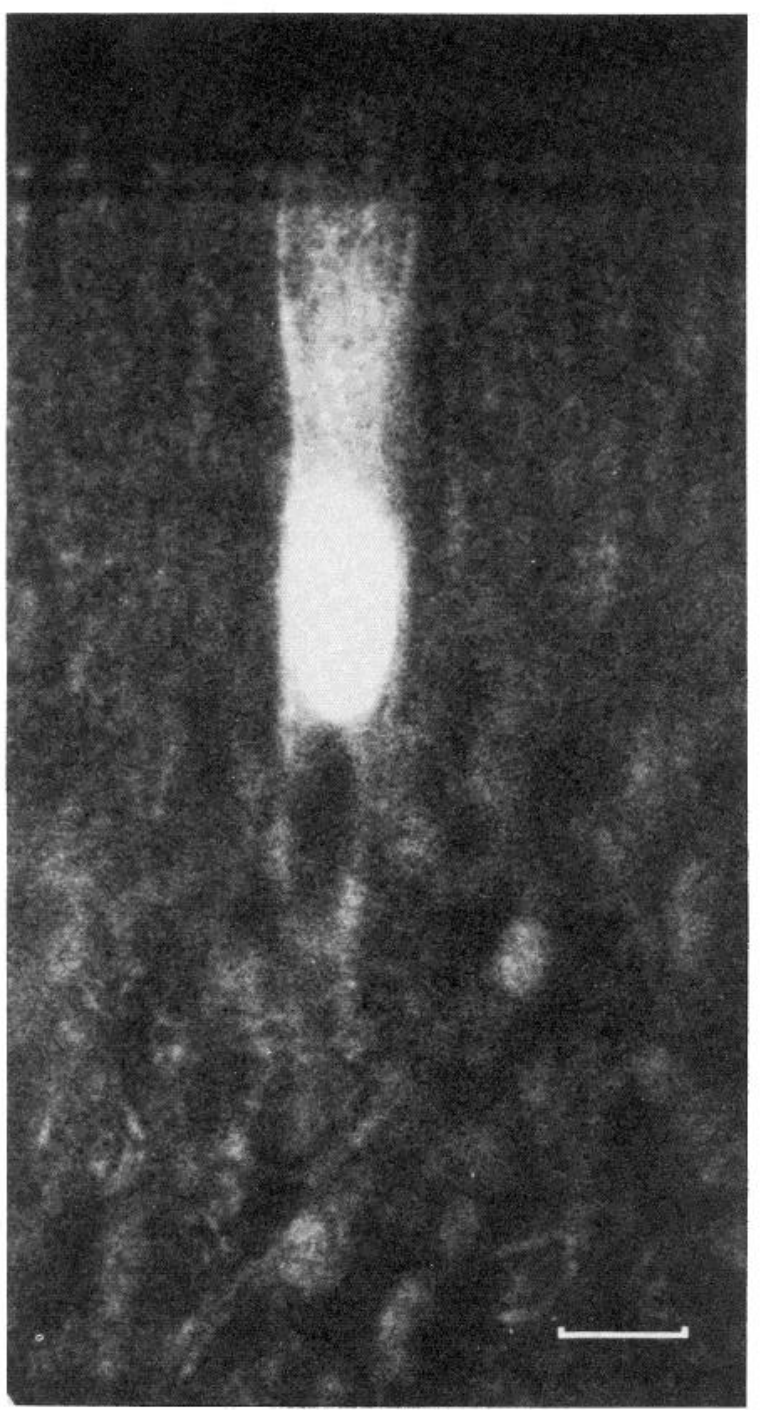

could be seen as a process 1 to $2 \mu \mathrm{m}$ in diameter coursing toward the mucosal surface of the epithelium. An axon, less than $1 \mu \mathrm{m}$ in diameter, was seen to pass deeper through the basal lamina and turn and run parallel to the lamina. Receptor neurons were usually positioned near the midportion of the epithelium when viewed with combined fluorescence and bright field. All cells that had this morphology $(n=8)$ showed the electrical responses described above.

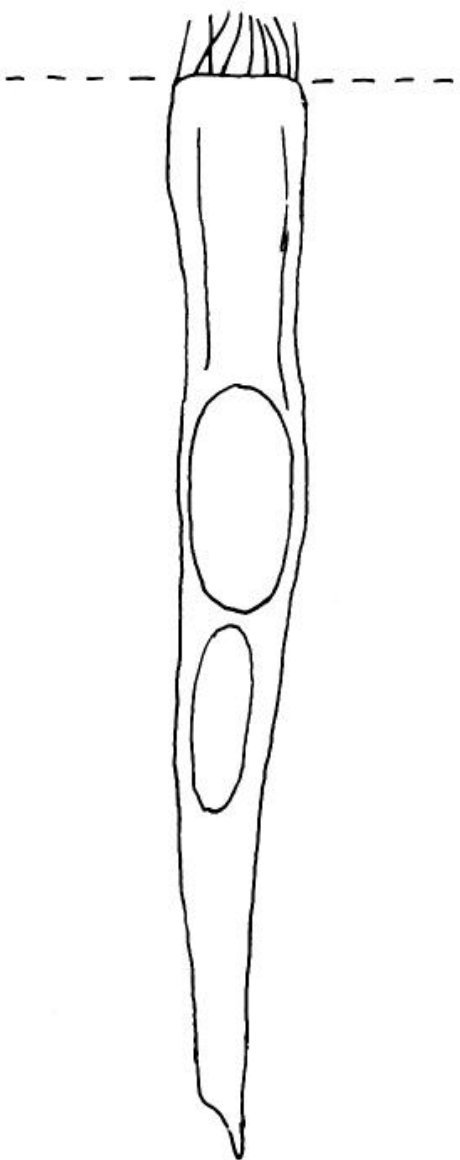

Figure 4. A cell injected with Lucifer Yellow, identified as a supporting cell by its morphology and electrical characteristics. $A$, The photomicrograph was taken with combined bright field and fluorescence illumination. Visible in the same layer as this cell are other columnar supporting cells; below are seen the outlines of the receptor cell nuclei. $B$, Drawing of the injected cell in $A$, showing the outlines of the cell body and nucleus and the microvilli projecting from the surface. The dotted line indicates approximately the upper margin of the epithelium. Calibration bar is $10 \mu \mathrm{m}$.
On many occasions, what appeared as partial penetrations of receptor neurons were observed. These recordings were characterized by membrane potentials of -20 to $-40 \mathrm{mV}$ and small repetitive action potentials $(10$ to $20 \mathrm{mV})$. One explanation is that these were penetrations of the receptor dendrite, since they were usually observed near the surface of the epithelium, and that the small amplitude of the spikes was due in part to injury by the penetration. 

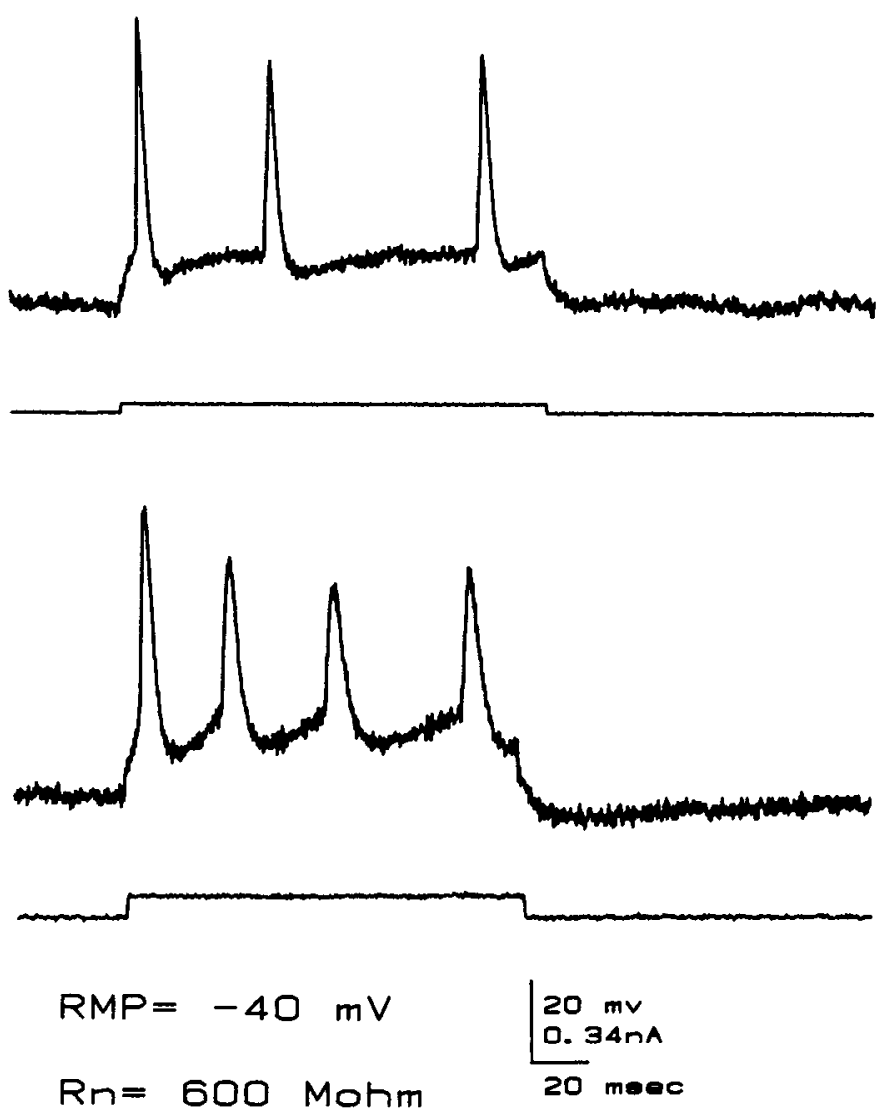

Figure 5. Impulse responses of a receptor neuron to depolarizing injected current pulses. With increasing current pulses, the frequency of firing increased from approximately $25 \mathrm{~Hz}$ (above) to approximately $35 \mathrm{~Hz}$ (below) (see text).

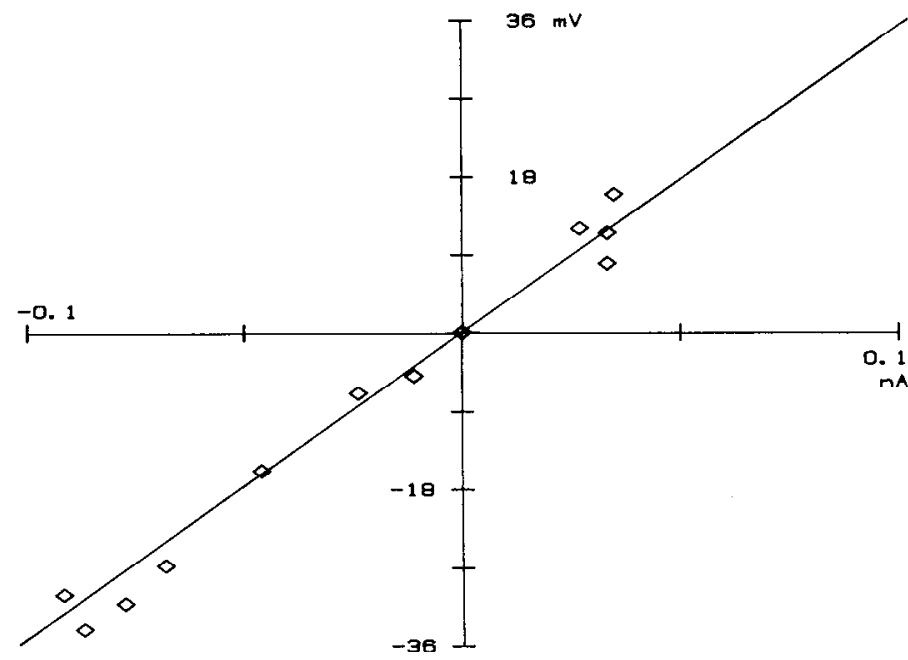

Figure 6. Current-voltage relationship for a representative receptor neuron. The I-V plot was linear in the hyperpolarizing direction, and in the depolarizing direction, up to threshold for spike initiation (slope resistance, 320 megohms).

Nonspiking receptor neurons. Another category of cell had resting membrane potentials and input resistances similar to those of receptor neurons, but it was not possible to generate action potentials in this cell with injected current (see Table 1). This category was encountered infrequently, and our physiological data are therefore limited. Our most complete data for one of these cells are illustrated in Figure 9. Note the linear I$\mathrm{V}$ relation for hyperpolarizing currents, and the significant

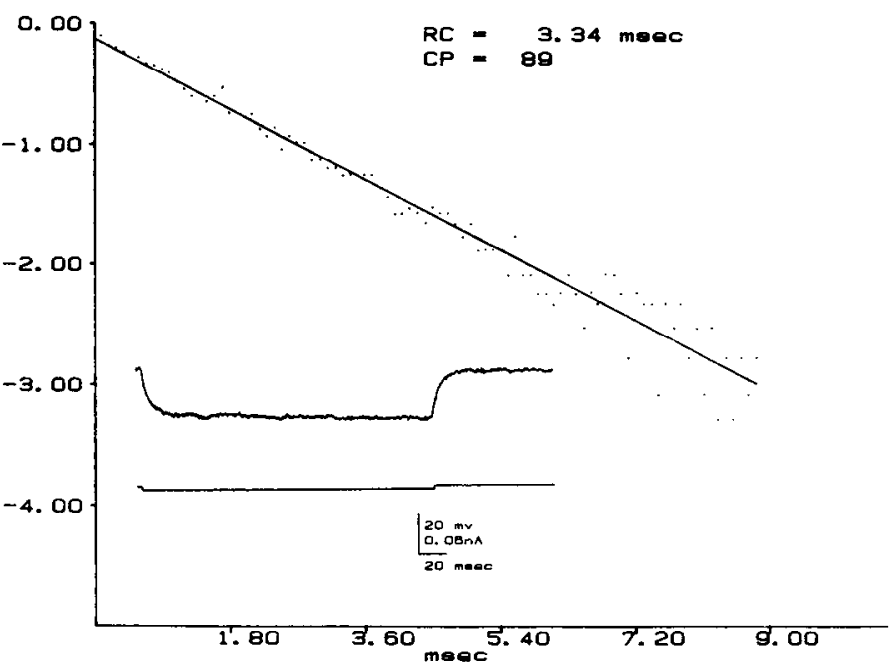

Figure 7. Analysis of the charging transient for a representative receptor neuron. Response to a hyperpolarizing current pulse is shown in the inset. Ordinate and abscissa are as in Figure 3. Plot shows membrane time constant $(R C)$ with a value of $3.34 \mathrm{msec}$. Note absence of equalizing time constants at brief times.

deviation from this linear relation with depolarizing currents. Analysis of the charging transient is illustrated in Figure 10, and summarized in Table 1 . The estimated value for the membrane time constant was significantly longer in this cell type than for either the supporting or mature receptor neuron types.

Because of their relatively infrequent occurrence, it was not possible to inject these cells successfully with Lucifer Yellow to identify them morphologically. Cells with these properties were encountered in the deeper part of the epithelium in the electrophysiological recordings. Their possible identity as immature receptor neurons is discussed below.

\section{Discussion}

Since the synthesis of the fluorescent dye Lucifer Yellow (Stewart, 1978), it has been possible to dye inject cells more easily, especially very small cells as in the present study. Here we have been able to mark definitively two cell types whose electrical characteristics were clearly distinct, and which we have previously suggested to be supporting cells and receptor neurons (Masukawa et al., 1983). We thus confirm the separate markings by Getchell (1977), of supporting cells, and Suzuki (1977), of receptor neurons, using Procion Yellow, but have more clearly shown the morphological distinction between these two cell types in the same preparation. In addition we have provided evidence for electrophysiological recordings from immature receptor neurons.

The use of electrical properties to classify cells was dependent on strict criteria. Because microelectrode penetrations can cause membrane damage, there was a need to have at least one criterion for each cell type that represented a reasonably healthy recording. In the case of the supporting cell, it was the high membrane potential; in the case of receptor and immature receptor neurons, it was the high membrane resistance. All other cellular recordings not falling into these groups were not included.

With regard to the notation for cell classification, we have previously used type I and type II to refer to physiological properties presumed to be associated with supporting and receptor cells, respectively (Masukawa et al., 1983). Concurrently Rafols and Getchell (1983) have used type I and type II to refer to morphological subclasses of supporting cells. On the basis of our present results, we will henceforth refer to type I and type II physiological classes as supporting cells and receptor neu- 
A

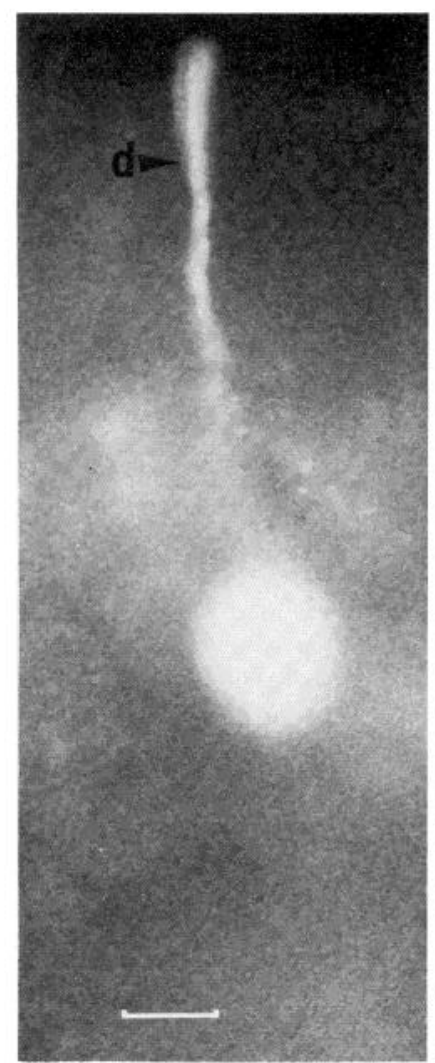

B

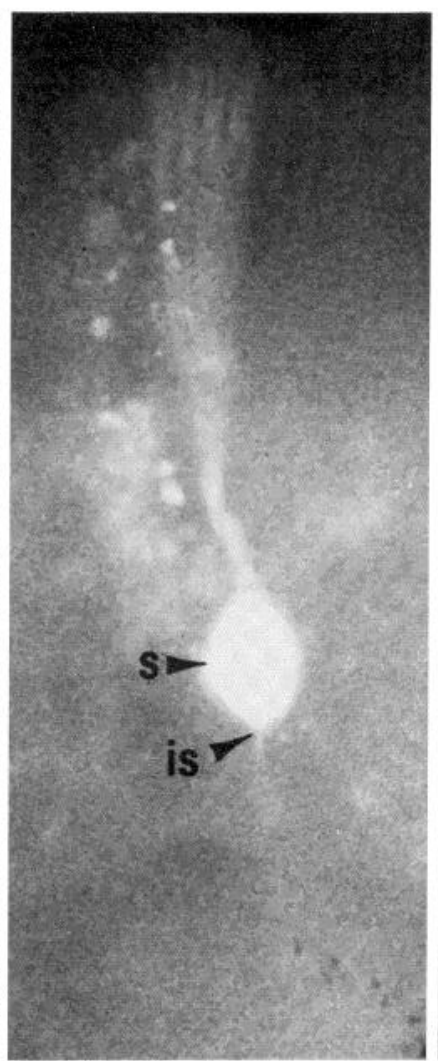

C

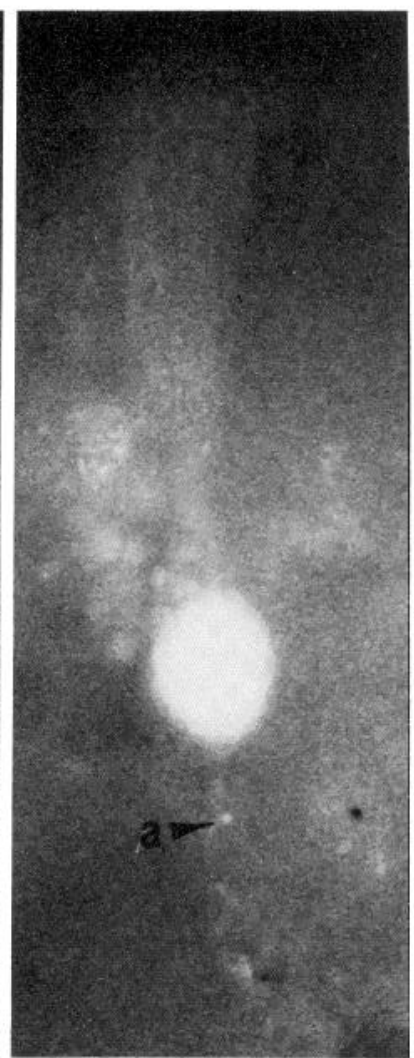

D

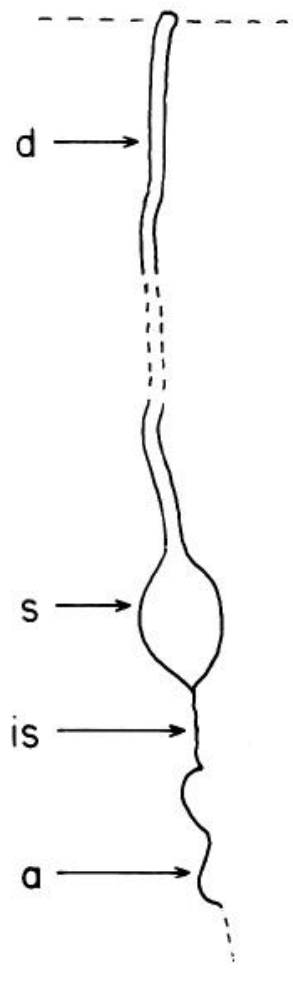

Figure 8. A cell injected with Lucifer Yellow identified as a receptor neuron by its morphology and electrical characteristics. $A, B$, and $C$ are fluorescence micrographs at three planes of focus: on the dendrite, cell body, and axon, respectively. $D$, composite drawing of the injected cell. Dotted lines indicate parts which were slightly out of focus. Indicated in the composite drawing are the dendrite $(d)$, soma $(s)$, intitial segment (is), and axon (a). The dashed horizontal lines indicate approximately the surface and basal lamina of the epithelium. Calibration bar is $10 \mu \mathrm{m}$.

rons, respectively, in order to avoid possible confusion with Rafols and Getchell's (1983) terminology for supporting cells.

\section{Supporting cells}

The supporting cells are a distinct population of cells which we have identified definitively with dye marking. These cells have been pointed out by Okano and Takagi (1974) and Getchell (1977) to be similar to glial cells. Electrically, they share a high resting membrane potential and a low input resistance (see Somjen, 1975). The rather high membrane potential that we have seen in supporting cells has also been noted in neuronal glial cells in cortex, where values have reached $-110 \mathrm{mV}$ (Gutnick et al., 1981). The extremely low input resistance, usually below 10 megohms, is also a characteristic of neuronal glial cells; it has been attributed to a high resting potassium conductance (Somjen, 1975, 1981).

Supporting cells never generated spikes. This not only indicates the lack of active properties in the membrane of the cells under the conditions of these experiments, but also indicates that the supporting cells are not electrically coupled to the spiking receptor neurons, which is consistent with morphological observations (Graziadei and Monti Graziadei, 1976). The supporting cells showed little evidence of rectification to injected current, within the range tested. The I-V relations for both the depolarizing and hyperpolarizing currents were linear within the range tested.

Gap junctions have been observed by Kerjaschki and Horander (1976) and R. Small (personal communication) although they are infrequent. The presence of electrical coupling between supporting cells has not, however, been demonstrated by dye injections; moreover, because of the extremely low membrane resistance, electrical connectivity may be present that may not be revealed by dye passage (Bennett et al., 1978; Gutnick et al., 1981; Knowles et al., 1981; Powell and Westerfield, 1984). It is therefore not possible to rule out electrical coupling purely on the basis of lack of dye coupling.

As is well known, supporting cells surround the receptor neurons, with the membranes of the two types directly apposed. Although the morphological data, as well as our physiological data, do not provide evidence for electrical or synaptic connections between the two, there is nonetheless communication between them, as shown by changes in the electrical properties of the supporting cells while the receptor neurons undergo degeneration. This will be demonstrated in the following paper (Masukawa et al., 1984).

\section{Receptor neurons}

The olfactory receptor neurons have been difficult to study by intracellular techniques because of their small size. There have been two previous intracellular studies of presumed receptor neurons in the in vivo salamander olfactory epithelium (Getchell, 1977; Trotier and MacLeod, 1983). This is the first study in the salamander in which it has been possible to stain the receptor neurons and correlate this cell type with physiological properties.

The several studies to date are in general agreement that the resting membrane potential is approximately $-50 \mathrm{mV}$, in salamander (Trotier and MacLeod, 1983; Getchell, 1977; Masukawa et al., 1983) and in lamprey (Suzuki, 1977), and that the input resistance is in excess of 100 megohms in salamander 


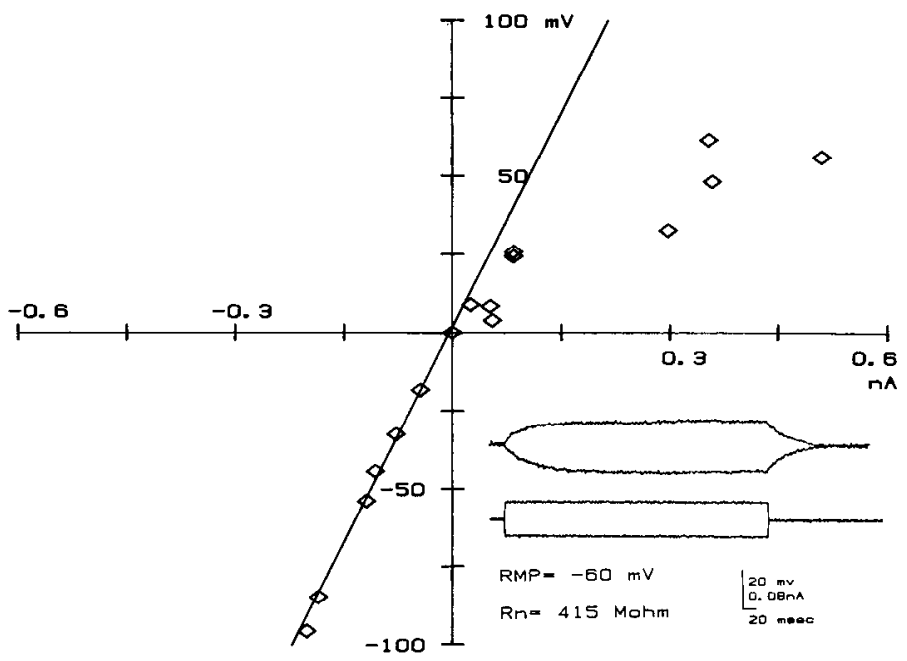

Figure 9. Current-voltage relations of a nonspiking receptor neuron, presumably an immature receptor neuron. Representative responses to current pulses for the cell are shown in the inset. The I-V relation was linear for hyperpolarizing currents (straight line fitted by computer), but a significant deviation from this linearity occurred with depolarizing currents. This cell did not generate action potentials in response to current injection regardless of the amount of depolarization.

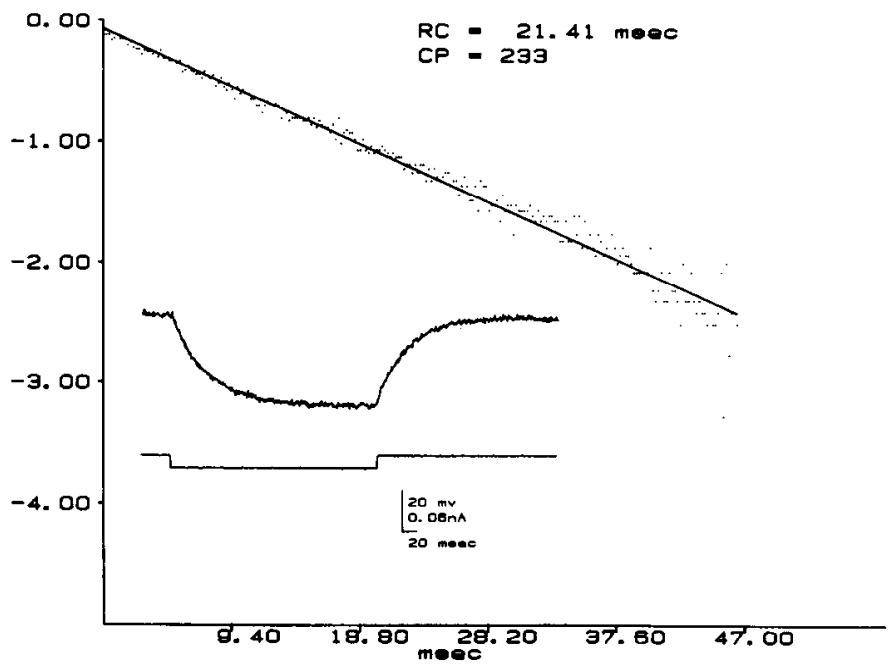

Figure 10. Analysis of the charging transient for a nonspiking receptor neuron. A representative response to a current pulse is shown in the inset. A membrane time constant $(R C)$ of $21.4 \mathrm{msec}$ was calculated from the linear plot.

(Masukawa et al., 1983; Trotier and MacLeod, 1983) and in lamprey (Suzuki, 1977). We have observed input resistances as high as 600 megohms (Masukawa et al., 1983). This high input resistance is compatible with results in rods (Bader et al., 1978), hair cells (Corey and Hudspeth, 1979), and taste bud cells (Roper, 1983) and may reflect a common feature of small sensory cells. This may also be a common and important property in small neurons and dendritic processes in general (see Shepherd, 1979). The high input resistance has important implications for the receptor mechanisms of olfactory neurons, as we will discuss elsewhere (Hedlund et al., 1984).

The current-voltage relations were linear for hyperpolarizing currents, and were linear for cells tested into the depolarizing range up to the generation of impulses. The intervention of the impulse discharge made it impossible to carry out equivalent measurements of voltage over the range of different current intensities. Suzuki (1977) did report membrane rectification with depolarizing currents, but this reflects the fact that the measurements were made during the afterpotential following an initial spike response to the depolarizing current pulse. Rectification of this type was also seen in our recordings.

In our experiments, the rectification was correlated with depression of action potential amplitude (see Fig. 5). Trotier and MacLeod (1983) observed no rectification to injected current but did observe depression of action potential amplitude during the odor response, indicating that rectification may have been present independent of the shunting effect of the generator conductance (see also Masukawa et al., 1983 and Fig. 5, this paper).

Our calculated membrane time constants (mean, $4.2 \mathrm{msec}$ ) were reasonably similar to the value of $5.62 \mathrm{msec}$ for a single receptor neuron reported previously by Suzuki (1977) in a lamprey olfactory neuron. The lack of a significant equalizing time constant in the charging transient analysis suggests that the olfactory receptor neuron, despite its elongated dendrite and cilia, is relatively compact electrotonically, with the injected current flowing almost instantaneously throughout the dendrite and cilia. On this assumption, using estimates of surface area of Golgi-impregnated receptor neurons (including the dendrite and cilia) reported by Rafols and Getchell (1983), a value of approximately $4,000 \mathrm{ohms} / \mathrm{cm}^{2}$ can be estimated for $R_{m}$. This fits with the value for the charging time constant, under the assumption of a value of $1 \mathrm{microfarad} / \mathrm{cm}^{2}$ for the membrane capacitance, $C_{m}$. Taken together with the high $R_{N}$ noted above, these considerations clearly show that the receptor neuron is very compact electrotonically. This provides for a very tight coupling between the site of receptor potential generation in the olfactory vesicle and/or cilia and the site of impulse initiation in the axon. We have recently confirmed this with a simulation of the olfactory receptor neuron using a computational model, and will report these results elsewhere.

The action potentials in receptor neurons had smooth rising and falling phases, giving little indication either of components related to sequential generation in the initial axonal segment and cell body (Eccles, 1957; Fuortes et al., 1957), or of dendritic spikes. The amplitude of the initial spike was characteristically somewhat larger than the resting membrane potential; this degree of overshoot indicates a site of generation not very far from the recording site. The maximum firing rate of the cells illustrated in Figure 5 of approximately 35 impulses/sec is within the range reported by Suzuki (1977). We did not test for maximum firing frequencies with longer current pulses.

\section{Nonspiking receptor neurons}

We observed a distinct population of cells in the deep half of the epithelium that shared the medium level of membrane potential and high input resistance of receptor neurons, but lacked the ability to generate action potentials. We have tentatively designated these as immature receptor neurons. We base this on the similarity of the electrical characterisitcs, and the hypothesis that the capacity to generate action potentials is dependent on the mature axon. In the following paper, we show that this category of cell is more frequent during the period of new receptor neuron differentiation following nerve transection (Masukawa et al., 1984).

The fewer penetrations of this cell type, compared with mature receptor neurons, could be due to a smaller cell size or more fragile membrane, as well as a smaller population (see Monti Graziadei and Graziadei, 1979). Degenerating receptor neurons are ruled out by the fact that they tend to be found near the surface of the epithelium (Graziadei and Monti Graziadei, 1976,1978 ), whereas the recordings were made mostly in the deep half of the epithelium. The other cell type that might contribute to these recordings is the basal cell or stem cell from which receptor neurons are derived. The stem cells divide and send off a daughter cell that differentiates into the 
receptor neuron. The precise identification will require more exhaustive cell marking.

An intriguing difference between this category and the mature receptor neuron is the significantly longer membrane time constant (mean, $21.6 \mathrm{msec}$ ). This may indicate a special property of either the membrane capacitance or membrane resistance in these immature neurons, but in the absence of morphological data further speculation is not warranted. Another interesting finding was the inward rectification revealed by the I-V plots (Fig. 9). It is possible that the depolarizing pulse turns on a conductance for potassium, similar to that described in other neurons and embryonic cells (Latorre and Miller, 1983).

\section{References}

Bader, C. R., Macleish, P. R., and Schwartz, E. A. (1978) Response to light of solitary rod photoreceptors isolated from tiger salamander retina. Proc. Natl. Acad. Sci. U. S. A. 75: 3507-3511.

Bennett, M. V. L., Spira, M. E., and Spray, D. C. (1978) Permeability of gap junctions between embryonic cells of fundulus: A reevaluation. Dev. Biol. 65: 114-125.

Corey, D. P., and Hudspeth, A. J. (1979) Ionic basis of the receptor potential in a vertebrate hair cell. Nature 281: 675-677.

Eccles, J. C. (1957) The Physiology of Nerve Cells, Johns Hopkins Press, Baltimore.

Fourtes, M. G. F., Frank, K., and Becker, M. C. (1957) Steps in the production of motoneuron spikes. J. Gen. Physiol. 40: 735-752.

Gesteland, R. C., Lettvin, J. Y., and Pitts, W. H. (1965) Chemical transmission in the nose of the frog. J. Physiol. 181: 525-559.

Getchell, T. V. (1977) Analysis of intracellular recordings from salamander olfactory epithelium. Brain Res. 123: 275-286

Getchell, T. V., and Shepherd, G. M. (1978) Responses of olfactory receptor cells to step pulses of odour at different concentrations in the salamander. J. Physiol. 282: 521-540.

Graziadei, P. P. C. (1971) The olfactory mucosa of vertebrates. In Handbook of Sensory Physiology. Vol. IV: Chemical Senses, Part 1: Olfaction, L. M. Beidler, ed., pp. 27-58, Springer-Verlag, New York.

Graziadei, P. P C., and Monti Graziadei, G. A. (1976) Olfactory epithelium of Necturus maculosus and Ambystoma tigrinum. J. Neurocytol. 5: $11-32$

Graziadei, P. P. C., and Monti Graziadei, G. A. (1978) Continuous nerve cell renewal in the olfactory system. In Handbook of Sensory Physiology. Vol. IX: Development of Sensory Systems, M. Jacobson, ed., pp. 55-83, Springer-Verlag, New York.

Gutnick, M., Connors, B., and Ransom, B. R. (1981) Dye coupling between glial cells in the guinea pig neocortical slice. Brain Res. 213: 486-492.

Hedlund, B., Masukawa, L. M., and Shepherd, G. M. (1984) The olfactory receptor cell: Electrophysiological properties of a small neuron. Soc. Neurosci. Abstr., in press.

Kerjaschki, D., and Horander, H. (1976) The development of mouse olfactory vesicles and their cell contacts: a freeze-etching study. J. Ultrastruct. Res. 54: 420-444.

Knowles, W. D., Funch, P. G., and Schwartzkroin, P. A. (1982) Elec- trotonic and dye coupling in hippocampal CA1 pyramidal cells in vitro. Neuroscience 7: 1713-1722.

Latorre, R., and Miller, C. (1983) Conduction and selectivity in potassium channels. J. Membr. Biol. 71: 11-30.

Masukawa, L. M., Hedlund, B., and Shepherd, G. M. (1981) Changes in the electrical properties of olfactory epithelial cells in the tiger salamander after olfactory nerve transection. J. Neurosci. 5: 136141.

Masukawa, L. M., Kauer, J. S., and Shepherd, G. M. (1983) Intracellular recordings from two cell types in an in vitro preparation of the salamander olfactory epithelium. Neurosci. Lett. 35: 59-64.

Monti Graziadei, G. A., and Graziadei, P. P. C. (1979) Neurogenesis and neuron regeneration in the olfactory systems of mammals. $J$. Neurocytol. 8: 197-213.

Moulton, D. G., and Fink, R. P. (1972) Cell proliferation and migration in the olfactory epithelium. In Olfaction and Taste IV, (D. Schneider, ed.), pp. 20-26, Wissenschaftlige Verlagsgesellschaft, Stuttgart.

Okano, M., and Takagi, S. F. (1974) Secretion and electrogenesis of the supporting cell in the olfactory epithelium. J. Physiol. 242: 353370.

Powell, S. L., and Westerfield, M. (1984) The absence of specific dyecoupling among frog spinal neurons. Brain Res. 294: 9-14.

Rafols, J. A., and Getchell, T. V. (1983) Morphological relations between receptor neurons, sustentacular cells and Schwann cells in the olfactory mucosa of the salamander. Anat. Rec. 206: 87-101.

Rall, W. (1977) Core conductor theory and cable properties of neurons. In Handbook of Physiology. Sect. 1: The Nervous System, Vol. 1: Cellular Biology of Neurons, E. R. Kandel, ed., pp. 39-97, The American Physiological Society, Bethesda.

Roper, S. (1983) Regenerative impulses in taste cells. Science 220: 1311-1312.

Shepherd, G. M. (1979) The Synaptic Organization of the Brain, Oxford University Press, New York.

Simmons, P. A., and Getchell, T. V. (1981a) Neurogenesis in olfactory epithelium: Loss and recovery of transepithelial voltage transients following olfactory nerve section. J. Neurophysiol. 45: 516-528.

Simmons, P. A., and Getchell, T. V. (1981b) Physiological activity of newly differentiated olfactory receptor neurons correlated with morphological recovery from olfactory nerve section in the salamander. J. Neurophysiol. 45: 529-549.

Simmons, P. A., Rafols, J. A., and Getchell, T. V. (1981) Ultrastructural changes in olfactory receptor neurons following olfactory nerve section. J. Comp. Neurol. 197: 237-257.

Somjen, G. G. (1975) Electrophysiology of neuroglia. Annu. Rev. Physiol. 37: 163-170.

Somjen, G. (1981) Physiology of glial cells. In Physiology of NonExcitable Cell, J. Salanki, ed., pp. 23-43, Academiai Kiado, Budapest.

Stewart, W. W. (1978) Intracellular marking of neurons with a highly fluorescent naphthalimide dye. Cell 14: 741-759.

Suzuki, N. (1977) Intracellular responses of lamprey olfactory receptors to current and chemical stimulation. In Food Intake and Chemical Senses, Y. Katsuki, M. Soto, S. F. Takagi, and Y. Omura, eds., pp. 13-22, Japanese Scientific Society Press, Tokyo.

Trotier, D., and MacLeod, P. (1983) Intracellular recordings from salamander olfactory receptor cells. Brain Res. 268: 225-237. 